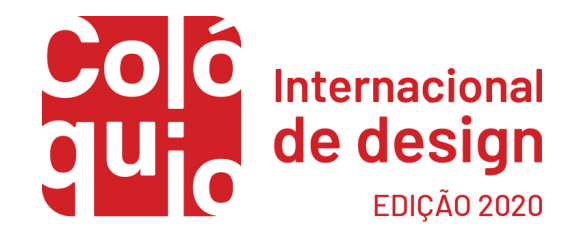

\title{
Em um instante banal
}

Igor Cesar Rosa;

André Villas-Boas;

Ana Karla Freire de Oliveira

resumo:

A observação do trabalho repetitivo em uma fábrica de vassouras, em uma visita técnica integrante de um estudo de materiais, gera reflexões sobre a atividade artesanal e o trabalho estranhado, tendo como referência artigos técnicos sobre o extrativismo da piaçava no litoral da Bahia, bem como os quadros teóricos de Marx, Chauí, Katinsky e Álvaro Vieira Pinto.

palavras-chave:

Artesanato; design sustentável; piaçava; trabalho estranhado; alienação do trabalho 
Por vezes, a observação de algo banal nos desperta, por razões não muito claras, para a reflexão crítica sobre o que fazemos, sobre as razões que nos move e, enfim, sobre nós mesmos. É coisa de um instante, uma fração de segundo, mas que se alonga no tempo porque toma uma forma maior em nossa mente, ultrapassando a banalidade de origem. Foi o que ocorreu durante uma visita técnica a uma fábrica de vassouras, uma atividade necessária à pesquisa para uma dissertação de mestrado, ora em andamento, com o tema do reaproveitamento de resíduos da fibra de piaçava para fins de design, junto ao Programa de Pós-Graduação em Design no âmbito da Universidade Federal do Rio de Janeiro (PPGD-EBA/UFRJ).

Naquela ocasião, a necessária observação do trabalho de um operário chamou a atenção pela monotonia das tarefas repetitivas que ele desempenhava, com zelo e até com certo humor, mas paradoxalmente com visível desinteresse. Um trabalho de aparência mecânica, um conjunto de gestos orientados por habilidade e força, como tantos outros tantas vezes já testemunhados, e executado tantas vezes por tantos outros trabalhadores, sem qualquer particularidade ou novidade frente a estes. Possivelmente, a centelha para as reflexões que se seguiram a esta cena tão corriqueira tenha sido o recente contato com uma tese de doutorado de autoria do designer Iraldo Matias, desenvolvida no âmbito da sociologia do trabalho. Em sua tese - infelizmente, pouco divulgada em nosso campo, embora trate de nossa atividade -, o autor observa que, na teoria do design,

"os trabalhadores simplesmente não são referenciados, senão indiretamente como o 'sujeito consumidor' e a figura do 'produtor' corresponde [unicamente] ao proprietário dos meios de produção [...]” (MATIAS, 2014: 32).

No retorno a casa, os pensamentos foram tomados por questões que se digladiavam, punham em dúvida umas às outras, esmagavam certezas para que estas em seguida ressurgissem altivas, num fluxo avassalador cuja importância se fazia óbvia mas que não se explicava diante do que o havia motivado. O que justificava aquela visita eram resíduos, era o material considerado lixo na produção das vassouras, e era por eles, por aquele lixo, que estávamos ali. Os resíduos que se espalhavam pelo chão e cercavam aquele trabalhador cujo corpo fazia sempre os mesmos movimentos, os mesmos procedimentos, a força e a destreza para algo que se encerrava em si mesmo, sem importância para ele próprio, e que ele faria por horas durante o dia, dias durante meses e possivelmente meses durante anos, aqueles resíduos tinham mais importância para nós do que o próprio homem; aquele lixo parecia nos ter mais valor do que aquele homem, e que qualquer outro homem. Inanimados e desprezados, eram àqueles resíduos que a pesquisa pretendia dar nova vida por meio da reciclagem; ao homem, parecia estar para sempre reservado aquele trabalho, desprezado e inanimado de razão.

A decantação daquelas reflexões levou à constatação - ora evidente, mas não naquele momento de turbulência - de que não há paradoxo na valorização daqueles resíduos como objeto de estudo, como se em detrimento da valorização do trabalhador. Tratava-se de uma falsa questão, porque estes termos não são excludentes per se. Não se trata necessariamente de minimizar ou ignorar as condições de trabalho daqueles que estão diretamente envolvidos no processo de produção, mas de centrar-se num tema que é próprio do campo do design, qual seja, o estudo dos materiais. Isto não significa necessariamente deixar de lado as questões relativas às relações sociais de produção e menos ainda rejeitar a reflexão de Matias (2014). Ao contrário: tais relações não configuram o foco da pesquisa - situação talvez mais afeita a outras áreas, como a sociologia, a filosofia ou a história -, mas não devem ser deixadas de lado, pois incidem diretamente no que move a própria pesquisa, ou seja, na utilização do design como atividade vinculada à ideia de um mundo melhor e mais justo (e é neste contexto nosso interesse pelo avanço do design sustentável).

Este artigo, que representa um estudo tangencial aos objetivos centrais da pesquisa em andamento, é o resultado daquele turbilhão de indagações, perplexidades, descrenças e ratificações que o instante de banalidade gerou.

\section{Pesquisa e pandemia}

Esta visita à fábrica, ainda no início de 2019, foi uma dentre as ocorridas para o cumprimento da segunda etapa do desenvolvimento da pesquisa, que versa sobre a aplicabilidade de um ecocompósito 
tendo como matérias-primas a resina à base de óleo de mamona reforçada por resíduos da fibra de piaçava, no universo do design sustentável.

A palavra piaçava se origina na expressão tupi-guarani pyae açaba, cujo significado é tecer, nó, juntar (SAMPAIO, 1955 apud GUIMARÃES \& SILVA, 2012:36), que pode ser atribuído a sua utilização original na confecção de cordas de alta resistência. A espécie por nós considerada é a obtida da palmeira Atallea funifera Martius, abundante no litoral da Bahia e especialmente na região sul deste, que é a área de maior produção da espécie no país. O Amazonas é o maior produtor da outra espécie comum no Brasil, a Leopoldinia piassaba. Outros nomes dados à piaçaveira da Bahia são piassaba, piaçaba, piassaba-da-Bahia, piaçava-da-Bahia, coco-de-piaçava e piaçaveira (GUIMARÃES \& SILVA, 2012). Rio de Janeiro e Minas Gerais aglutinam a maior parte da comercialização da produção baiana.

O objetivo da pesquisa é analisar a viabilidade do uso combinado de resíduos de fibra de piaçava com resina poliuretana derivada do óleo de mamona. Para isso, o estudo se desdobra em:

- revisar a literatura que abrange o universo dos ecocompósitos;

- descrever e analisar a metodologia de fabricação das vassouras de piaçava e caracterizar o resíduo oriundo deste processo;

- pesquisar a respeito da fibra de piaçava enquanto elemento de reforço para ecocompósitos poliméricos;

- estudar a resina poliuretana derivada de óleo da mamona (Ricinus communis) observando seu uso em ecocompósitos e suas possibilidades reais na produção e na composição de objetos com menor impacto ao meio ambiente.

Assim, a metodologia de pesquisa, ilustrada pela figura 1, se configura primeiramente em uma revisão bibliográfica para fundamentação. Posterior e concomitantemente, foram realizadas as visitas técnicas às empresas que fabricam vassouras de piaçava, com o intuito de caracterizar e coletar resíduos da fibra. A fase seguinte é a da experimentação em laboratório e da realização de ensaios técnicos visando à caracterização do ecocompósito, para verificação, por fim, das possibilidades reais de uso do material fabricado em projetos de design sustentável. As restrições causadas pela notória necessidade de isolamento social em decorrência da pandemia da covid-19 têm dificultado ou adiado tais atividades que, no entanto, se mantém como nosso propósito.

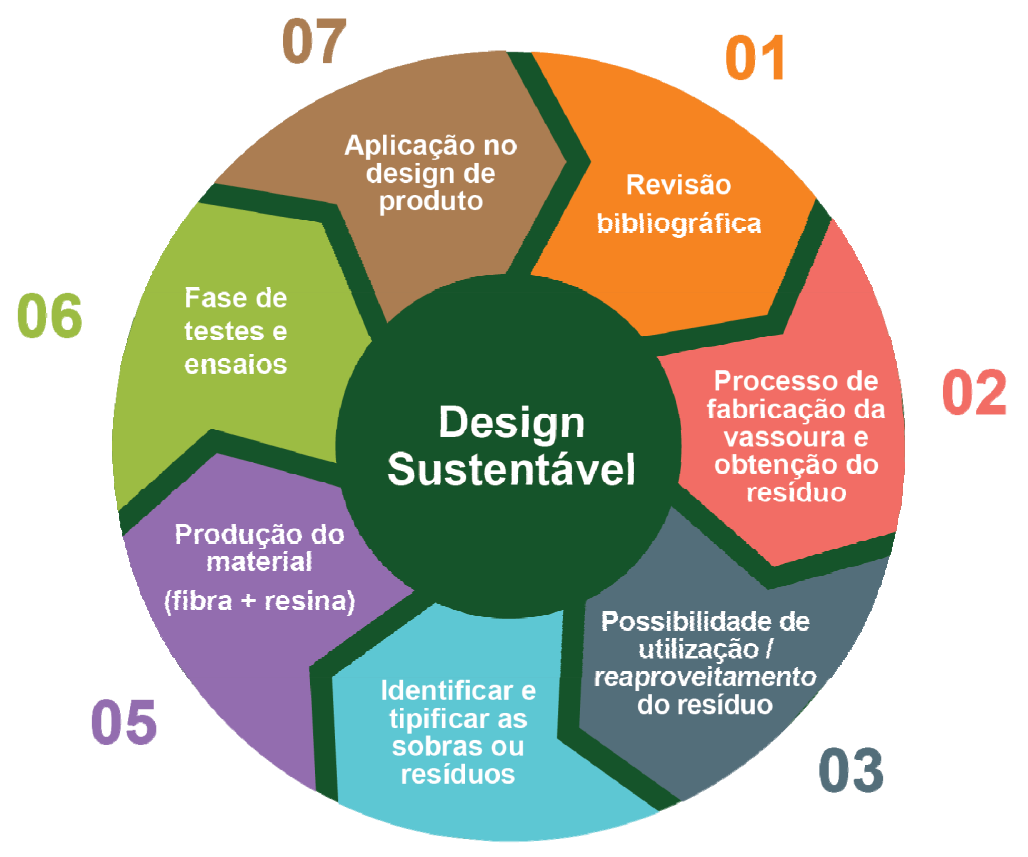

Figura 1 - Representação da metodologia da pesquisa. Fonte: Os autores, 2019. 
O enfoque é a busca por novos materiais e produtos que apresentem um impacto menor no meio ambiente, no universo do design, da arquitetura e da engenharia. Compósitos reforçados com fibras vegetais têm despertado grande interesse de pesquisadores e profissionais da área de materiais.

Nas visitas que fizemos às fábricas, verificamos que os resíduos da piaçava usada na produção são vistos como lixo, sem potencialidade de reaproveitamento. No entanto, ROCHA et al. (2016) observam que certos tipos de resíduos comumente descartados estão dentre os que têm sido cada vez mais utilizados nos ecocompósitos, por suas características físico-mecânicas não alcançadas por outros materiais, além de serem economicamente vantajosos. Este parece ser o caso da piaçava durante o processo de produção de vassouras.

Ainda que esteja nesta fabricação a principal destinação da piaçava, em sua região de origem ela é largamente utilizada no artesanato. As palmeiras da Bahia produzem fibras longas, resistentes, rígidas, lisas, de textura impermeável, de alta flexibilidade, e que conservam a elasticidade quando umedecidas (ESQUENAZI, 2019). Estas propriedades, aliada ao fato de o material ser comum no litoral baiano, fazem com que em torno da piaçava se organizem, naquela região, comunidades voltadas para a produção artesanal com forte viés identitário. Foi justamente este dado - a discrepância entre os dois cenários, o da fábrica e o das comunidades - que nos ajudou a equacionar o turbilhão de reflexões provocado por aquele instante de banalidade na fábrica de vassouras.

\section{A produção manual que parece mecânica}

Embora nos dois cenários as mesmas fibras sejam trabalhadas, é notável a valorização do material junto à troca de experiências no trabalho artesanal, em contraposição à dinâmica do trabalho na fábrica de vassouras - que, por vezes, se irmanam pelo próprio gestual que a transformação pelo trabalho imprime ao material. O sentimento que é percebido nas comunidades de tradição artesanal, como se verá à frente, não se estabelece na produção de vassouras. Nesta, o manejo da piaçava, mesmo que predominante manual (e, por isso, o ressaltamos com o uso do termo manejo), se confunde com o da escala industrial. É inevitável a aparência de algo mecânico, mesmo que numa atividade manual, e é justamente esta contradição que nos levou às reflexões que serão expostas mais ao fim deste artigo.

Seja para a fabricação de vassouras no Sudeste ou para o artesanato local, a piaçava da Bahia é obtida por meio do extrativismo, ainda que nas últimas décadas tenha havido tentativas - algumas exitosas - de seu cultivo sistemático por meio da lavoura (MATTOS, 2002; GUIMARÃES \& SILVA, 2012). Conforme MATTOS (2002), no sudeste baiano, onde a produção se destina quase que exclusivamente para a venda destinada à produção de vassouras,

A mão-de-obra empregada na extração da piaçava é quase que exclusivamente de cortadores sem vínculo empregatício com os proprietários. É constituída por trabalhadores especializados nas tarefas referentes à atividade - corte, limpeza da fibra e amarração - que prestam serviços nas propriedades piaçaveiras na época da colheita. A remuneração por seu trabalho é por produção, sendo o pagamento efetuado no momento de pesagem dos produtos [...]. São moradores de vilas situadas nas áreas de produção, ou de cidades nas periferias dessas áreas [...]. Essa mão-de-obra pode ser contratada diretamente pelo proprietário, pelo meeiro do proprietário, ou pelo comprador da piaçava [...]. A mão-de-obra fixa nas propriedades de piaçava é mínima quando esta é a única atividade agrícola do estabelecimento. Geralmente é constituída por um ou dois homens [...] (MATTOS, 2002:23-24).

PIMENTEL (2015) atribui as técnicas de extração das fibras da piaçava a uma herança cultural dos índios tupinambás, que as utilizavam para compor objetos trançados. É por meio da transmissão oralizada, há várias gerações, que ocorre a troca de conhecimento e experiência acumulada por comunidades tradicionais que manipulam produtos florestais não madeireiros, como os grupos de ribeirinhos, seringueiros, sertanejos, caiçaras, quilombolas e indígenas.

Para complementar a importância do manejo da piaçava, GUIMARÃES e SILVA (2012) informam que: 


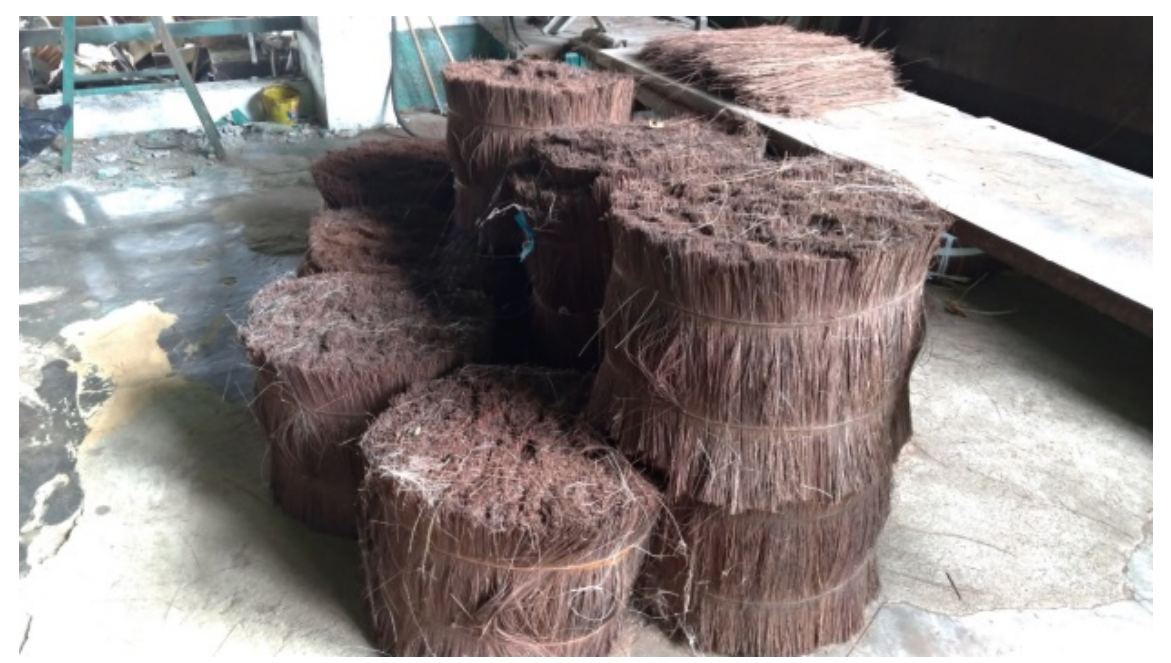

Figura 2 - Rolos de piaçava, tal como chegam às fábricas. Foto dos autores.
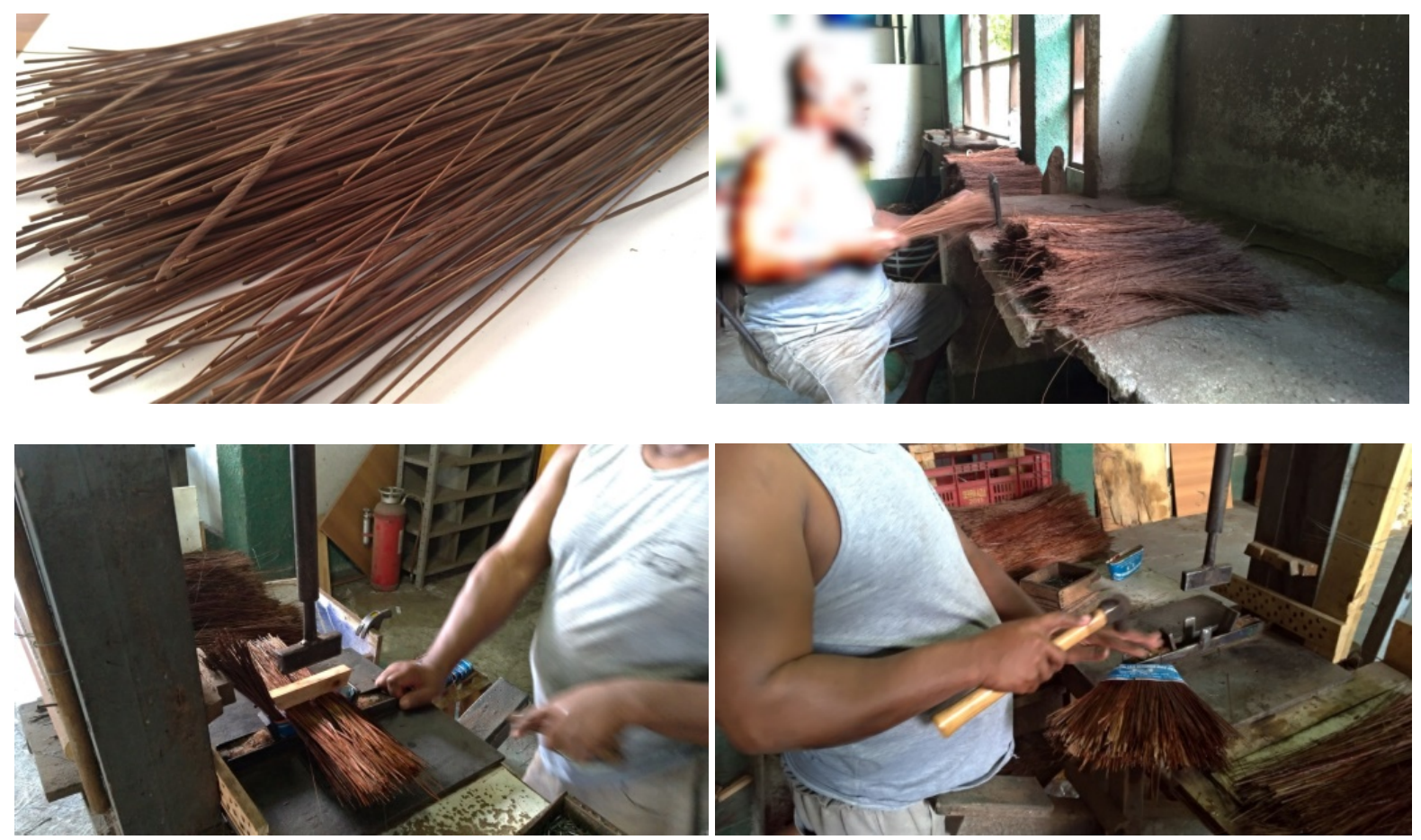

Figura 3 - Sequência de etapas da fabricação das vassouras, do alto à esquerda, em sentido horário: Feixe de fibras para separação entre longas e curtas; penteamento das fibras; prensando e fixando as fibras na base de madeira e lata. Fotos dos autores.
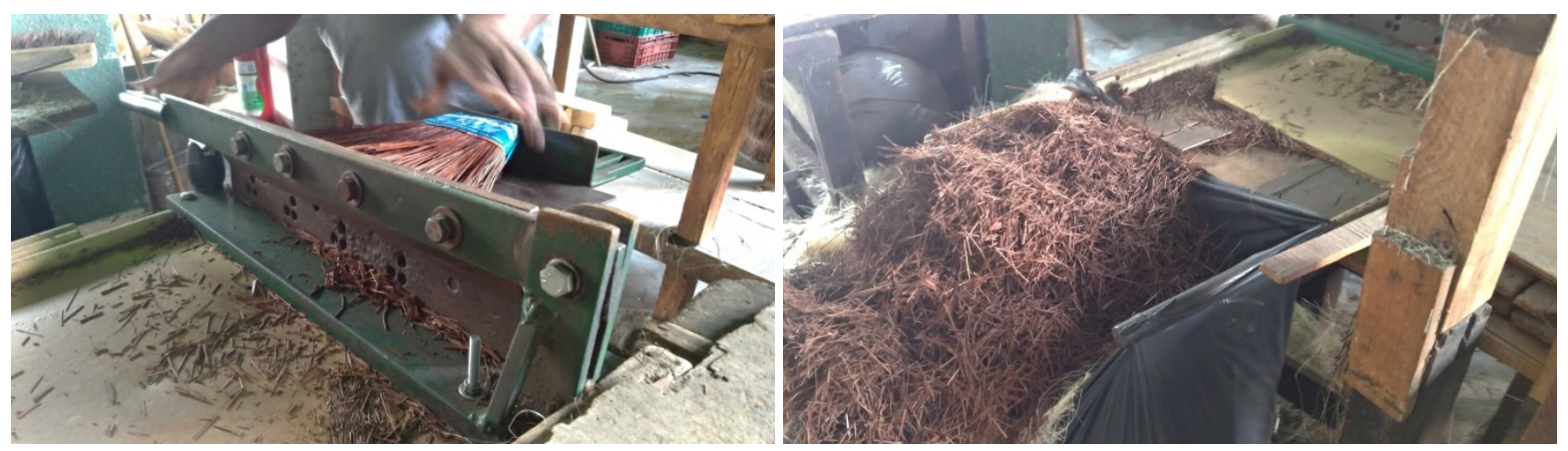

Figura 4 - Resíduos de piaçava. Fotos dos autores. 
Colhe-se a piaçava bruta, formada pelas fibras piaçava e borra juntas, de cada folha em senescência [envelhecimento]. A folha também é cortada próximo à base do pecíolo [a haste que a liga ao caule], para facilitar a retirada do produto, mas nunca arrancada integralmente da planta porque pode criar condições favoráveis ao ataque de pragas. Com esta prática, parte das fibras permanece na palmeira para ser aproveitada no corte seguinte. Entre uma colheita e outra, esta base da folha seca ou entra em decomposição e [sic] já no corte seguinte se aproveita as fibras deixadas no ano anterior, as quais são denominadas "toco". Este, por ser a parte basal da fibra, em geral é grosso e duro e tem cerca de $50 \mathrm{~cm}$ de comprimento. Geralmente os homens sobem nas piaçaveiras e colhem as fibras, e as mulheres e adolescentes separam a fibra piaçava da fibra borra o que resulta em dois produtos: piaçava e borra (GUIMARÃES \& SILVA, 2012:169).

Após a extração, as fibras são vendidas para fabricas de vassouras, sem que sejam separadas as que são longas das curtas (figura 2). Esta separação é realizada nas próprias fábricas, por meio do processo de penteamento, no qual também são limpas. Nas visitas técnicas a estas fábricas, tal como naquela citada neste artigo, foi possível acompanhar o processo de fabricação manual do produto (figura 3).

Ele consiste numa sequência de repetições. Ou seja: trata-se de um processo manual mas que se torna simbolicamente mecanizado por sua repetitividade. A etapa do acabamento encerra o processo. É nela que ocorre o acúmulo de resíduos (figura 4) e são estes resíduos que, como observado anteriormente, são considerados simplesmente como lixo por boa parte destas empresas, que não identificam neles qualquer potencialidade de aproveitamento.

\section{A criação de si mesmo no artesanato}

O contraponto que utilizamos para refletir sobre aquele instante de banalidade no cenário da fábrica é um segundo cenário: o de algumas comunidades do litoral baiano, em regiões pródigas em palmeiras Attalea funifera Martius e que estão distantes entre si por cerca de cinco horas, em trajeto de ônibus ou carro (figura 5). Diferentemente do que ocorreu com as fábricas de vassouras, não pudemos observar in loco estas experiências, devido ao isolamento social provocado pela disseminação do coronavírus, que agravou outras dificuldades. Por isso, partimos de fontes bibliográficas e também de fotos e vídeos jornalísticos. Especialmente com relação aos vídeos, buscamos adotar uma postura cautelosa e crítica, dada a sua tendência à romantização, comum quando a temática é a da valorização do artesanato.

Até há alguns anos, antes do incremento do turismo na região, o artesanato a partir da piaçava (figura 6) era um dos principais motores econômicos do então pequenino povoado de Porto de Sauípe. Tal como nas demais comunidades aqui mencionadas, para as mulheres que desenvolvem a atividade naquele distrito do município de Entre Rios, a piaçava não é um material sem história, meros rolos amarrados sem qualquer vínculo com aquele que imprimirá nela uma transformação pelo trabalho. Embora os dois cenários trabalhem com as mesmas fibras, é notável a valorização do material em conjunto à troca de experiências no trabalho artesanal em Porto de Sauípe, assim como nas outras comunidades, embora elas tenham diferenças entre si. O trabalho transforma o material da origem deste (figura 7) até sua transformação no produto final:

A piaçava é retirada das palmeiras [...] em um processo cuidadoso que respeita a vegetação e preserva o replantio. A cada 3 meses, novas folhas nascem e estão prontas para utilização. Tanto a retirada [das matas da região] quanto o transporte da matériaprima até a sede é feita pelas artesãs. Como qualquer outra forma de construção, a produção de artesanato acontece por etapas, sendo elas: Coleta, cozimento, riscagem, tingimento, trançado e costura.

1. Colheita: Separar a palha na cor amarela da parte central da palmeira.

2. Cozimento: A palha é colocada em uma panela com água para cozinhar e assim interromper o processo de deterioração da matéria orgânica, evitando que apodreça depois. Após o cozimento as palhas são postas para secar enrolada em largos anéis podendo ficar quatro ou cinco dias até estarem completamente secas. 
3. Riscagem: As palhas são separadas em tiras.

4. Tingimento*: Esta etapa é opcional, sendo feita quando quer mudar a coloração da palha. O tingimento é feito através de um novo cozimento com água e corantes naturais, como capianga que deixa amarelo e cipó de rego que deixa vermelho.

5. Trançado: É a trança específica da região feita na palha.

6. Costura: Etapa final para o acabamento do produto.

Além da palha, as artesãs utilizam corantes naturais e artificiais (anilina). As ferramentas utilizadas na produção são: faca, tesoura, agulha, fita métrica e pedra de seixo (para polir as peças). A produção contempla: bolsas, esteiras e cestos, dentre outros artefatos (SILVA et al., 2018:888-889).

A trançagem da palha, comumente realizada em grupo (figura 8), lembra uma orquestra em atividade, mas na qual as mãos são os instrumentos e o maestro é a habilidade passada de geração para geração. As mãos não param. E, como que aplaudindo de pé a cada execução de uma partitura, vão surgindo pouco a pouco os resultados do trabalho - que, pelo próprio processo artesanal, são diversos uns dos outros.

Focando na comunidade de Massarandupió, mais ao norte, mas também em Entre Rios, o relato de feição quase etnográfica da bióloga Rosane Oliveira Barreto corrobora o quão longe dos rolos de piaçava estão aquelas artesãs. Lá, como observa a autora, "avós, mães e netas ainda trabalham juntas" nas tarefas que redundam em bolsas, chapéus, tapetes e outros produtos:

No período de agosto a dezembro de 2009 , em que estive com as piaçaveiras, pude acompanhá-las passo a passo durante a confecção do artesanato.

O trabalho começa com a saída das artesãs em direção ao local da colheita, bem no início da manhã, quando o sol está fraco, ou no final da tarde.[...]

Segui com duas artesãs, Ivone e Edileuza, na sua rotina diária de trabalho, para a colheita das palhas, indo junto para ajudar a carregar e retirar as palhas um pescador chamado Regis da Caipora, nome dado por ele mesmo:
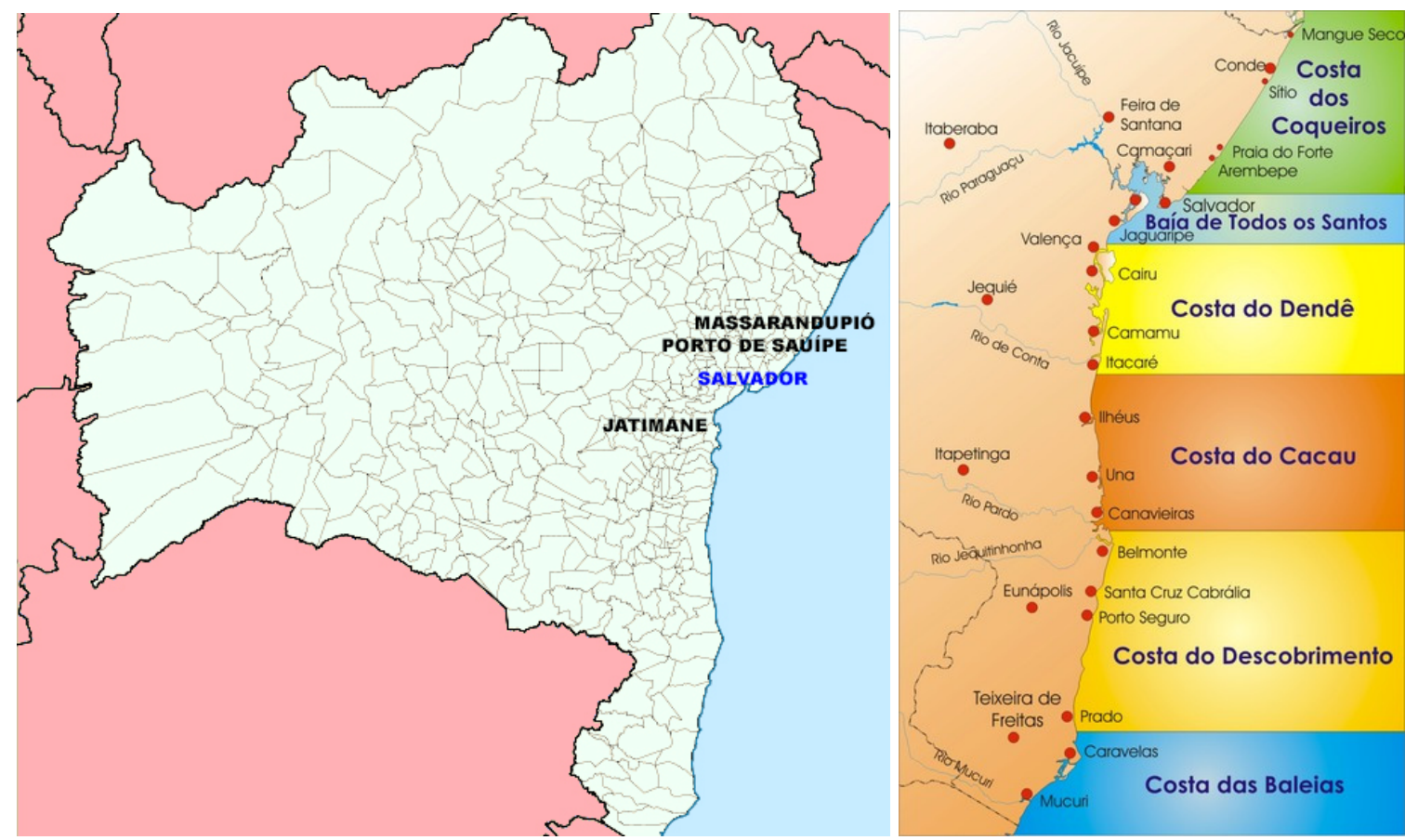

Figura 5 - Mapa do estado da Bahia, com localização aproximada das comunidades citadas. Fonte: Elaborado pelos autores.

À direita, localização das costas turísticas, estabelecidas pelo governo do estado. Fonte: Laboratório de Estudos Costeiros, em https://www.lec-ufba.org/projetos/costas-da-bahia.html. Acesso em 5 ago. 2020. 
Meu nome mesmo é Regis, mas pode me chamar de Regis da Caipora. É isso mesmo, sou Caipora porque gosto de cuidar do mato, quando caço é porque sinto fome e preciso comer, não é todo dia que o mar tá pra peixe. Ah, também afugento os homens que vêm destruir a piaçava de forma errada.

E foi aí que Regis da Caipora revelou a forma correta de saber quando a piaçava está pronta para a retirada das palhas:

Essa piaçava quando é muito nova é pobre, porque a palha é pequena, é menor, precisa ser mais larga, mais amarelada. Não se pode retirar a folha da mesma piaçava sempre, tem que esperar um tempo pra ela crescer e ter novas palhas, senão termina matando a piaçava.

[...] Durante a colheita, perguntei se elas tinham tomado curso para saber como retirar as palhas da piaçava.

Nós crescemos vendo nossas mães entrando no mato e retirando as palhas, mas aqui no Litoral Norte sempre vem pessoas do Sebrae, Mauá, Talentos do Brasil, Programa Berimbau e até agrônomos dar curso pra gente.

A gente também faz troca, eles vêm pra aqui dar curso e nós vamos pra lá mostrar como a gente trabalha com o nosso produto. Vamos até para Tocantins. Tem até uma artesã que foi pra África ensinar o trançado, porque na África também se faz o trançado.

(BARRETO, 2009:88-90; os grifos, que identificam a transcrição de falas, são da autora)

Neste segundo cenário, há a troca de experiências e de conhecimento e uma rica relação entre as artesãs e o próprio material, em torno da criação de objetos que mostram sua identidade e cultura própria. O que é mais valorizado por esses grupos tradicionais, a fibra ou o momento em que se reúnem para o trabalho com ela? É um ponto de reflexão crucial a relação familiar no trabalho com a fibra de piaçava, a tradição passada de mãe para filha, em relações sociais de produção que envolvem afetividade e que se convertem em associações e cooperativas, produtoras de objetos únicos que são postos à venda com certo orgulho mas, principalmente, como criação de si mesmas: a criação da peça é a própria artesã que a criou, porque ela não tem com aquela sua produção o estranhamento que o trabalhador da fábrica tem com a dele. Este ponto - a categoria de trabalho estranhado e suas implicações (MARX, 2010; RANIERI, 2011) - abordaremos somente um pouco mais à frente.

A predominância das mulheres no trato com a piaçava não se repete em outra comunidade, a do quilombo Jatimane, localizado na zona rural do município de Nilo Peçanha, na região da Costa do Dendê. Em sua grande maioria, as cerca de 70 famílias que vivem no povoado tiram seu sustento da piaçava, mas poucos se dedicam ao artesanato - cuja peculiaridade local é o intenso uso conjunto da fibra com o coco da piaçaveira na produção de bijuterias (figura 9). Metade da população atua no extrativismo e quase a mesma quantidade no beneficiamento para a produção de vassouras (mas não na fabricação delas). Algumas famílias plantam e vendem dendê, pescam e têm pequenos bares. Construíram uma escola municipal de ensino fundamental e um posto de saúde, com uma enfermeira.

A distribuição de trabalho entre homens e mulheres é marcante: aos homens cabe a responsabilidade de realizar o extrativismo propriamente dito da piaçava, e envolve a realização da colheita e o transporte para a comunidade; já às mulheres compete à realização do beneficiamento inicial da piaçava, e nesta etapa é realizada a limpeza com separação da fibra da casca (fita). Ainda no processo de beneficiamento, é comum nas comunidades o preparo de pentes de piaçava [...] [para cobertura de quiosques] e a confecção de artesanatos [...] da fibra da piaçava. Os pentes são feitos de forma coletiva, envolvendo mão de obra masculina e feminina, já o artesanato é uma atividade exclusivamente desenvolvida por mulheres (DITT, 2013:7)

A relação com o entorno é visceral, bem como a vida comunitária:

[...]em geral a população destas comunidades se constitui de famílias simples com baixo poder aquisitivo, vivendo do trabalho direto com os recursos naturais da área 

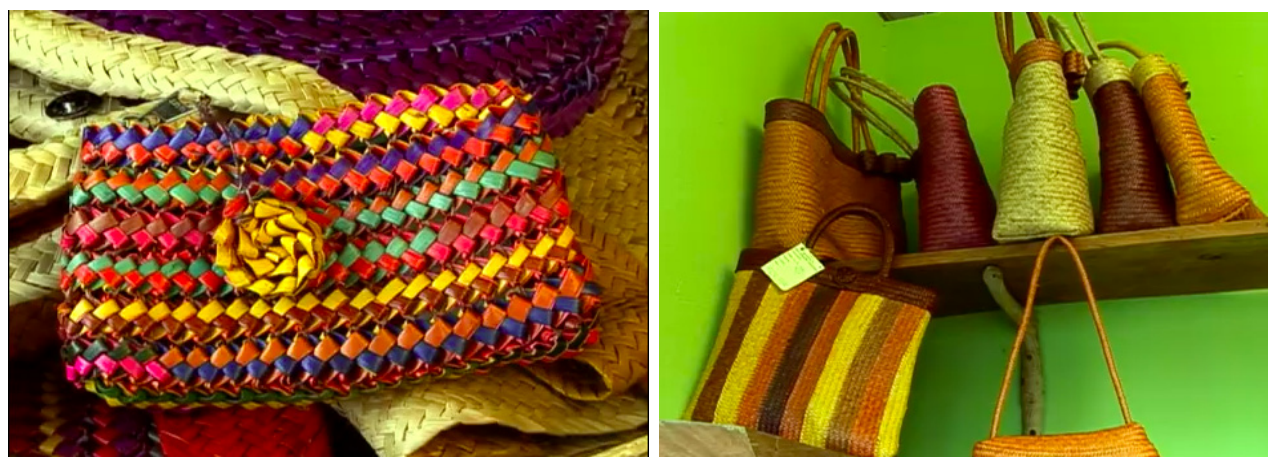

Figura 6 - Peças de artesanato confeccionadas em Porto de Sauípe com palha de piaçaba. Fonte: http://g1.globo.com/bahia/videos/t/todos-os-videos/v/artesanato-gera-emprego-e-renda-em-porto-do-sauipeba/2851326/. Acesso em 12 dez. 2019.

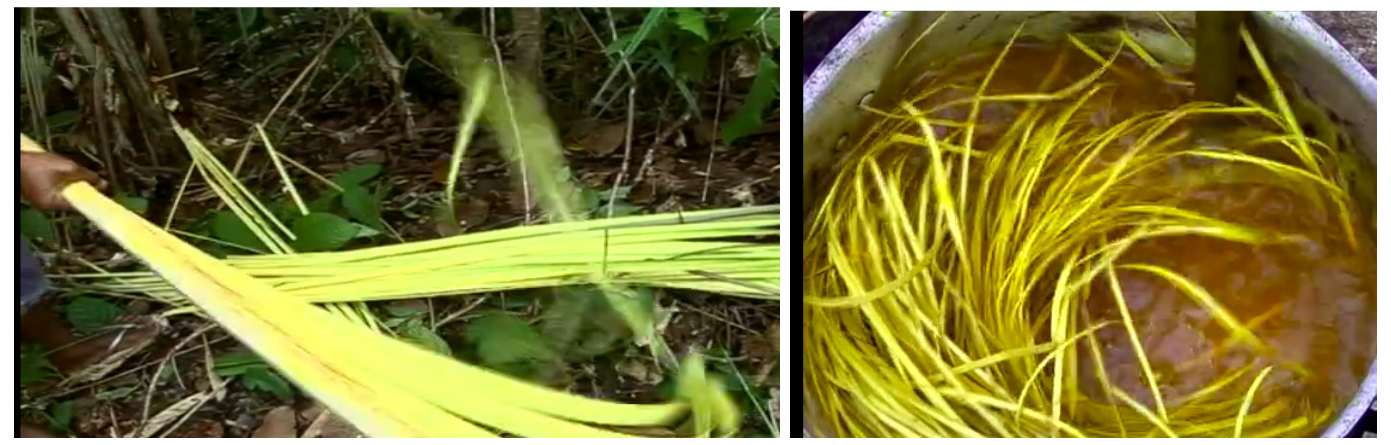

Figura 7 - Recolhimento (à esq.) e tingimento da palha de piaçava. Fonte:

http:/g1.globo.com/bahia/videos/t/todos-os-videos/v/artesanato-gera-emprego-e-renda-em-porto-do-sauipeba/2851326/ . Acesso em 12 dez. 2019.
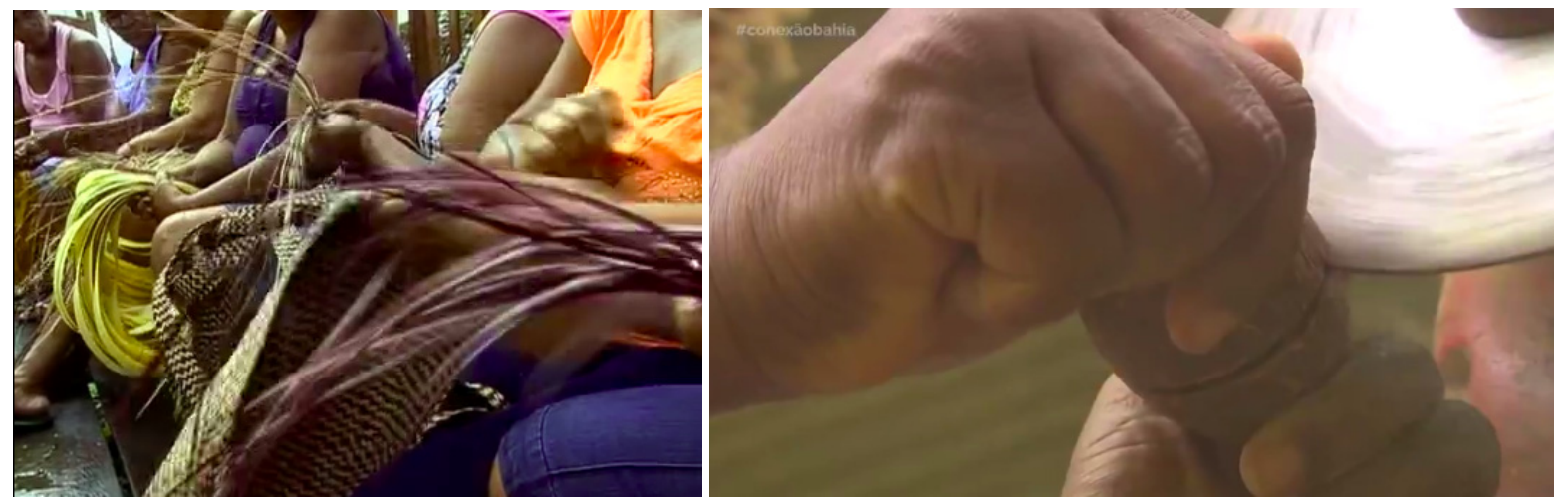

Figura 8 - À esquerda, a orquestra de mãos regida pela habilidade, no trabalho das artesãs de Porto de Sauípe. Fonte: http://g1.globo.com/bahia/videos/t/todos-os-videos/v/artesanato-gera-emprego-e-renda-em-porto-dosauipe-ba/2851326/. Acesso em 12 dez. 2019. À direita, o corte do coco, para confecção de bijuterias e outras peças no quilombo Jatimane. Fonte: https:/gshow.globo.com/Rede-Bahia/conexao-bahia/noticia/conheca-aproducao-artesanal-feita-de-piacava-no-quilombo-jatimane.ghtml. Acesso em 22 jul. 2020.
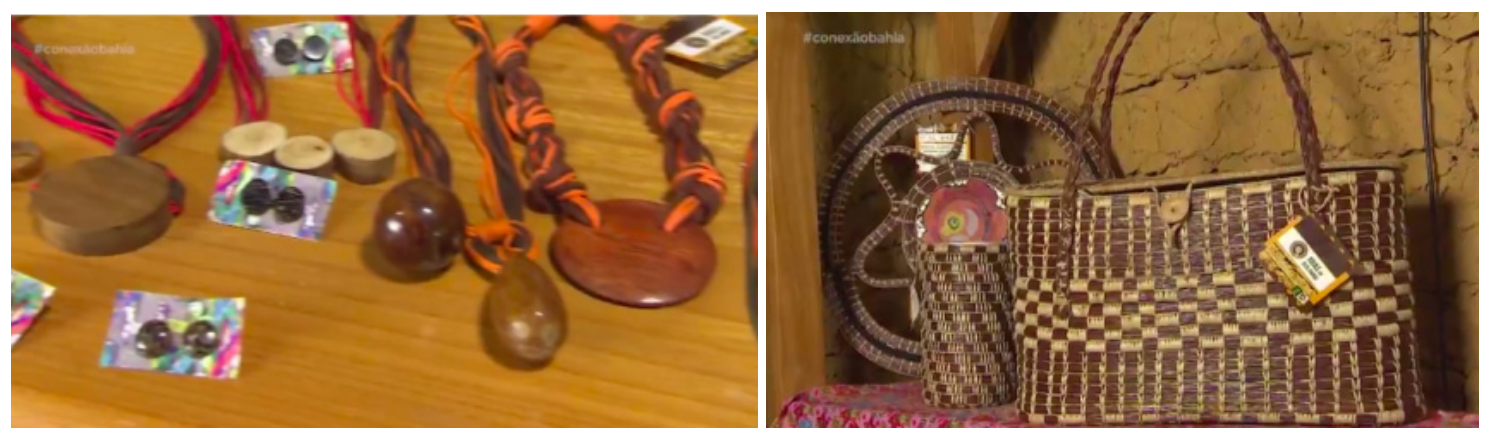

Figura 9 - Bijuterias e bolsas do artesanato do quilombo Jatimane. Fonte: https://gshow.globo.com/RedeBahia/conexao-bahia/noticia/conheca-a-producao-artesanal-feita-de-piacava-no-quilombo-jatimane.ghtml. 
[...]. É grande a dependência das famílias com as áreas que ocupam, não só em função da consolidação da moradia e atividade econômica, como na dependência das relações sociais e comunitárias estabelecidas localmente. Em geral, todas as famílias vivem de atividades de exploração de recursos naturais da região, o que faz delas ainda mais dependentes localmente (ibid., p.4).

Com a referência acima, é possível refletir que um conjunto de conhecimentos, tarefas, projetos, produtos compartilhados em um grupo, no qual uma dada produção artesanal se faz tradição, permite que esse grupo ou a comunidade tenham uma identidade.

A marca da comunidade é a indivisão interna e a ideia de bem comum; seus membros estão sempre numa relação face-a-face (sem mediações institucionais), possuem o sentimento de uma unidade de destino, ou de um destino comum, e afirmam a encarnação do espírito da comunidade em alguns de seus membros, em certas circunstâncias (CHAUÍ, 2008:57).

A essa indivisibilidade, a autora contrapõe a noção de sociedade:

Ora, o mundo moderno desconhece a comunidade: o modo de produção capitalista dá origem à sociedade, cuja marca primeira é a existência de indivíduos, separados uns dos outros por seus interesses e desejos. Sociedade significa isolamento, fragmentação ou atomização de seus membros, forçando o pensamento moderno a indagar como os indivíduos isolados podem se relacionar, tornar-se sócios. Em outras palavras, a comunidade é percebida por seus membros como natural (sua origem é a família biológica) ou ordenada por uma divindade (como na Bíblia), mas a sociedade impõe a exigência de que seja explicada a origem do próprio social (ibidem, 57-58).

Não nos parece imprudente a hipótese de que, nos casos aqui observados, a origem natural destas comunidades não só está na própria natureza - as matas, as palmeiras Atallea funifera Martius, o pertencimento à terra e à terra historicizada pelos conhecimentos e tradições acumulados - mas no trabalho, e no trabalho da própria matéria que constrói esse sentido comunitário: a piaçava como criação de si mesmos, os artesãos, nos objetos que produzem.

\section{Olhando 0 artesanato mais de perto}

Ricardo Lima (2002), pesquisador do Centro Nacional de Folclore e Cultura Popular (a denominação oficial do que conhecemos como Museu do Folclore), vinculado ao Iphan, discute alguns dos discursos acerca do artesanato. De um lado, há o entendimento do objeto artesanal como testemunho de um passado a ser preservado, principalmente por mantê-lo nas condições em que foram feitos. De outro, o discurso da transformação do objeto, no qual ele deixa de conservar sua originalidade, criando uma nova forma, um novo modelo, para atender ao que seriam as demandas do mercado.

Em uma breve conceituação sobre o artesanato, ele afirma que:

No mundo contemporâneo existe uma enorme gama de objetos que podemos definir como artesanato. São produtos do fazer humano em que o emprego de equipamentos e máquinas, quando e se ocorre, é subsidiário à vontade de seu criador que, para fazê-lo, utiliza basicamente as mãos. Nesse sentido, diríamos que o objeto artesanal é definido por uma dupla condição: primeiro: o fato de que seu processo de produção é em essência manual. São as mãos que executam basicamente todo o trabalho. Segundo: a liberdade do artesão para definir o ritmo da produção, a matéria prima e a tecnologia que irá empregar, a forma que pretende dar ao objeto, produto de sua criação, de seu saber, de sua cultura (LIMA, 2002:1-2).

A essência manual na produção permite uma liberdade na elaboração dos objetos que, assim, embutiriam o sentimento e a expressão do artesão - embora, como se verá a seguir, esta manualidade 
não seja determinante para o que KATINSKY (2008) irá supor como um artesanato moderno. CANCLINI (1983), porém, busca reequacionar a questão sobre a preservação ou transformação:

Muitos estudos a respeito das culturas populares surgiram a partir desta pergunta apocalíptica: o que se pode fazer para evitar que o capitalismo acabe com o artesanato e com outras manifestações tradicionais? Antes de procurar a resposta, deve-se perguntar se a pergunta está bem formulada. Ela deve ser repensada com base numa visão mais complexa de como o modo de produção vigente reproduz e renova a sua hegemonia. [...] nem o Estado nem a classe dominante estão interessados em abolir a produção artesanal. Nenhuma classe hegemônica pode exercer o seu poder e a sua ideologia através de uma arbitrariedade total, unicamente de cima para baixo; ela necessita, especialmente nas suas etapas históricas progressistas, do avanço do conjunto da sociedade. Quer seja através de um desenvolvimento tecnológico e econômico que integre a todos os setores sociais, incluindo as suas formas peculiares de produção material e cultural, quer seja porque precisa melhorar o nível educativo e de consumo das classes subalternas para expandir a produção e o mercado, o projeto dominante inclui muito mais do que a classe que o formula (CANCLINI, 1983:72).

Esta constatação do autor, que tem como contexto a cultura indígena do México, nasce de sua observação de que o artesanato funciona como contrapartida à homogeneização própria da dinâmica social capitalista, num "processo que 'estandartiza' o gosto e substitui a louça ou a roupa de cada comunidade por produtos industriais padronizados" (idem, p. 65).

Mas de modo simultâneo as exigências de renovar vez por outra a demanda não permitem que a produção se estanque na repetição monótona de objetos uniformizados. Contra os riscos de uma entropia no consumo, recorre-se à introdução de inovações na moda e ao processo de ressignificação publicitária dos objetos [...] (loc. cit.).

E, assim,

O capitalismo engendra os seus próprios mecanismos para a produção social da diferença, mas também utiliza elementos alheios. As peças de artesanato podem colaborar nesta revitalização do consumo, já que introduzem na produção em série industrial e urbana - com um custo baixíssimo - desenhos originais, uma certa variedade e imperfeição, que por sua vez permitem que se possa diferenciá-las individualmente e estabelecer relações simbólicas com modos de vida mais simples, com uma natureza nostálgica ou com os índios artesãos que representam esta proximidade perdida (loc. cit.).

No artigo já mencionado anteriormente, LIMA (2002) ressalta cinco pontos característicos para uma definição do artesanato:

- O artesanato não é mera mercadoria e traz embutido em si valores, crenças, culturas;

- Artesanato não é produto de máquina. Sendo manual, ele é irregular, "perfeitamente irregular";

- O artesanato não é algo imutável;

- Artesanato é ritmo; artesanato é tempo de produção;

- Artesanato pressupõe autoria e, portanto, tem a ver com os direitos do autor.

Em seu conhecido texto Design moderno, KATINSKY (2008) sustenta que, diferentemente do que parece ser consensual, o artesanato não corresponde a uma etapa pré-capitalista cuja permanência, em maior ou menor grau, estaria ligada às noções de atrasado ou obsoleto. Para o autor, não se verifica uma tendência efetiva da substituição do artesanato pela indústria, que o levaria gradativamente ao 
desaparecimento. Porém, seu argumento é diverso daquele de Canclini: para além de sua prática em ambientes pré-capitalistas ou tradicionais, o artesanato, em sua feição moderna, é para Katinsky um modo de produção utilizado na própria sociedade industrial e integrante dela. Afirma o autor:

Podemos definir o artesanato, qualquer que ele seja, como um modo de produção onde:

a) o uso de máquinas está sempre subordinado ao operador;

b) o número de operadores é relativamente pequeno mas, de qualquer modo, cada operador domina integralmente todas as operações necessárias para obter o bem proposto;

c) investimento em material e instrumentos é modesto em relação à qualificação do operador (KATINSKY, 2008, não paginado).

Assim, a manualidade não definiria este artesanato de feição moderna identificado pelo autor, mas o fato de que este utiliza-se de máquinas não "para economizar tempo ou mão-de-obra (como na grande indústria) mas tão somente para comodidade do operador". Assim, classifica seis tipos de artesanato presentes nas sociedades industrializadas, sem prejuízo nem marginalidade de sua inserção nela, mas, ao contrário, como sua partícipe. Como exemplo, lista entre os produtos artesanais da modernidade os aparelhos de precisão para a pesquisa científica que têm produção em pequena escala ou mesmo apenas por encomenda.

A originalidade da proposta do autor parece esbarrar em três problemas. O primeiro deles se refere ao rigor teórico: a caracterização proposta configura talvez um processo de produção, mas não um modo de produção. Esta última expressão se refere a uma categoria de amplo uso nas mais diversas áreas das ciências sociais que consiste na maneira como uma sociedade é organizada para a produção e que necessariamente embute feições particulares tanto das forças produtivas quanto das relações sociais de produção.

Não nos parece adequado, pelas três características apontadas no artigo, considerar que elas particularizem um modo de produção que não seja o modo de produção capitalista. E não se trata de um purismo teórico: mais alguns parágrafos à frente, tentaremos mostrar como a identificação desta indiferenciação foi determinante para nossas reflexões.

O segundo problema é que esta concepção parece apontar para uma substituição da preponderância da manualidade, como definidora do conceito de artesanato, pela da produção em pequena escala (em oposição à produção em série). Mas a produção em pequena escala, ou mesmo de exemplares únicos, não se vislumbra como o distintivo da atividade artesanal. Fosse assim, a simples obtenção de uma fotocópia seria fruto de artesanato - o que nos parece um equívoco.

Mas o terceiro problema é o que mais nos interessa, porque nos deu uma pista importante para entendermos por que a banalidade daquele instante na fábrica de vassouras nos ecoou tão fundo. Ao confundir modo de produção com processo de produção, o artigo em questão nos fez lembrar trechos - talvez excessivamente enérgicos, mas certamente oportunos - de O conceito de tecnologia, obra de publicação póstuma de Álvaro Vieira Pinto:

O homem é um ser destinado a viver necessariamente na natureza. Apenas, o que se entende por "natureza" em cada fase histórica corresponde a uma realidade diferente. Se no início era o mundo espontaneamente constituído, agora que o civilizado consegue cercar-se de produtos fabricados pela arte e pela ciência, serão estes que formarão para ele essa nova "natureza" (PINTO, 2005:37)

E prossegue, mais à frente:

A técnica torna-se não um substantivo, categoria gramatical, mas uma substância, categoria física, um ser, uma coisa. [...] Tendo sido porém propositadamente abandonados o eixo do processo histórico gerador de todas as técnicas [...] só resta o recurso das considerações abstratas, intentando relacionar a técnica, erroneamente substantivada, com o homem, também desligado do contexto social. (ibid., p. 50) 
Assim, não é o processo, a técnica, o que nos chamou a atenção naquela fábrica ao observar o trabalhador, porque a feição repetitiva de seus gestos não diferia tanto daquela que verificamos nas artesãs do litoral baiano. E, ao nos voltarmos para elas, verificamos, como observa RANIERI (2011:130), que "o lugar da interação entre o homem e a natureza é a atividade, ou seja, movimento de unidade entre sujeito e objeto" (grifo nosso):

[...] o objeto que é produto dessa atividade é extensão de uma existência subjetiva, ou seja, é exteriorização da capacidade humana para a consecução dessa mesma atividade. Como resultado da atividade, o produto é aquela forma por meio da qual a apropriação da natureza é apropriação humana, objetivação da atividade do sujeito: o objeto enquanto objetivação do gênero humano. Ao mesmo tempo que aparece como relação histórica entre ser humano e natureza, o trabalho acaba por determinar também o conjunto da vida humana, ou seja, como mediador, ele satisfaz necessidades tornando o gênero humano, na sua apropriação da natureza, cada vez mais um gênero para-si mesmo (loc. cit., grifos do autor).

É por esta perspectiva que escrevemos, algumas páginas atrás, que "a criação da peça é a própria artesã que a criou, porque ela não tem com aquela sua produção o estranhamento que o trabalhador da fábrica tem com a dele". É a categoria de estranhamento que nos deu luz para entender a razão daquele turbilhão de questões que nos tomou de volta à casa: naquele instante banal reconhecemos, atônitos por não compreendermos o que se passava com nós mesmos, a própria corporificação, ali, diante de nós, do trabalho estranhado.

\section{Juntando as pontas: parece mecânico, mas é estranhado}

O material manipulado pelo trabalhador da fábrica é o mesmo (e provavelmente comunga da mesma origem geográfica) que é manipulado pelas comunidades artesanais do litoral baiano. Esse vínculo entre as duas situações de trabalho realçou a diferença das condições em que ele se dá num caso e no outro, fazendo-nos problematizar a própria noção de trabalho. E ela está embutida na imagem comparativa da melhor abelha e do pior arquiteto, comumente citada por professores para realçar a noção de projeto, tão cara a nossa área:

Uma aranha executa operações semelhantes às do tecelão, e uma abelha envergonha muitos arquitetos com a estrutura de sua colmeia. Porém, o que desde o início distingue o pior arquiteto da melhor abelha é o fato de que o primeiro tem a colmeia em sua mente antes de construí-la com a cera. No final do processo do trabalho, chegase a um resultado que já estava presente na representação do trabalhador no início do processo, ou seja, um resultado que já existia idealmente. Isso não significa que ele se limite a uma alteração da forma do elemento natural; ele realiza neste último, ao mesmo tempo, a finalidade pretendida, que, como ele bem o sabe, determina o modo de sua atividade com a força de uma lei, à qual ele tem de subordinar sua vontade (MARX, 2017:255-256).

Mas o que nos chamou a atenção é a ressalva que o filósofo alemão sublinha no trecho imediatamente seguinte, que dá continuidade a seu raciocínio:

E essa subordinação não é um ato isolado. Além do esforço dos órgãos que trabalham, a atividade laboral exige a vontade orientada a um fim, que se manifesta como atenção do trabalhador durante a realização de sua tarefa, e isso tanto mais quanto menos esse trabalho, pelo seu próprio conteúdo e pelo modo de sua execução, atrai o trabalhador, portanto, quanto menos este último usufrui dele como jogo de suas próprias forças físicas e mentais (idem, 256).

O trabalho humano, portanto, jamais é mecânico - embora possa ter esta aparência, tal qual observamos naquela fábrica - e menos ainda se dá de forma instintiva, pois depende não só da atenção 
do agente como de sua vontade. Ou seja: depende de sua determinação em executá-lo, ainda que, como prática social, ela seja motivada por determinações acima de sua própria vontade. Sendo este aspecto hipoteticamente mecânico uma mera aparência, não é ele que distingue o trabalho do operário da fábrica daquele da artesã da comunidade rural. Ambos - ressalte-se: também o trabalho da artesã incluem procedimentos repetitivos que envolvem uma possível monotonia e aproximação a uma metafórica robotização. O que os difere é a compreensão da categoria de trabalho alienado, ou trabalho estranhado.

$\mathrm{O}$ uso destes termos envolve um debate teórico sobre o qual nos furtamos a discorrer. Como defende o tradutor, Jesus Ranieri (em MARX, 2010:15-16) - que é pesquisador na área da sociologia do trabalho e foi orientador da tese de doutorado que citamos logo na abertura deste artigo -, haveria uma sutil diferença no emprego dos termos Entäusserung (alienação) e Entfremdung (estranhamento) em Marx (2010), obra na qual o autor alemão discorre de forma seminal sobre a concepção de trabalho. Tanto porque foge às dimensões deste texto como porque também à nossa própria consistência teórica neste campo, preferimos acompanhar o tradutor em seu uso de estranhamento.

O trabalhador se torna uma mercadoria tão mais barata quanto mais mercadorias cria. Com a valorização do mundo das coisas [...] aumenta em proporção direta a desvalorização do mundo dos homens [...]. O trabalho não produz somente mercadorias; ele produz a si mesmo e ao trabalhador como uma mercadoria, e isto na medida em que produz, de fato, mercadorias em geral. [...] Este fato nada mais exprime, senão: o objeto que o trabalho produz, o seu produto, se lhe defronta como um ser estranho, como um poder independente do produtor. O produto do trabalho é o trabalho que se fixou num objeto, que se fez coisal, é a objetivação do trabalho. A efetivação do trabalho é a sua objetivação. Esta efetivação do trabalho aparece [...] como desefetivação do trabalhador, a objetivação como perda do objeto e servidão ao objeto, a apropriação como estranhamento, como alienação (MARX, 2010:80; grifos do autor].

Em consequência,

$\mathrm{Na}$ determinação de que o trabalhador se relaciona com o produto de seu trabalho como (com) um objeto estranho estão todas estas consequências. [...] quanto mais o trabalhador se desgasta trabalhando, tanto mais poderoso se torna o mundo objetivo, alheio que ele cria diante de si, tanto mais pobre se torna ele mesmo, seu mundo interior, (e) tanto menos (o trabalhador) pertence a si próprio. [...] $\mathrm{O}$ trabalhador encerra a sua vida no objeto; mas agora ela não pertence mais a ele, mas sim ao objeto. Por conseguinte, quão maior esta atividade, tanto mais sem-objeto é o trabalhador. Ele não é o produto do seu trabalho. Portanto, quanto maior este produto, tanto menor ele mesmo é (ibid., p. 81; grifos do autor; neste citação, tanto quanto na anterior, suprimimos as identificações de termos originais alemães, traindo o rigor do tradutor).

\section{Considerações finais}

Se nosso objetivo com o design sustentável não tem apenas razões de economia e produtividade, mas a busca por um mundo mais harmonioso e justo num planeta cujo perecimento não seja determinado por nós, é porque é no homem que, no limite, estamos pensando. Aquele instante tão banal, mas que por tanto se alongou para nós, foi justamente a reafirmação desta constatação: encarnado nos tempos e movimentos daquele trabalhador, o trabalho estranhado, o pertencimento dele ao objeto em detrimento de si mesmo, nos tornou patente que nossos estudos, como este da valorização dos resíduos das fibras da piaçava, só fazem sentido se vierem a contribuir para a emancipação do homem. E é justamente por isso que nós estudamos. 
Upon a banal instant

Abstract: A simple view to repetitious work in a broom factory, during technical visit to a materials study, generates reflections on the artisanal activity and the estranged labor, having as reference technical articles on the extraction of piassava on the coast of Bahia, as well such as the theoretical frameworks of Marx, Marilena Chauí, Júlio Katinsky and Álvaro Vieira Pinto.

Keywords: handicraft; sustainable design; piassava; estranged labor; alienated labour

\section{Referências bibliográficas}

BARRETO, ROSANE O.. Técnicas de manejo e sustentabilidade da palmeira attalea funifera Martius Piaçava da Bahia: Estudo de caso em Massarandupió, in: Candomblé, v.5, n.2, jul./dez. 2009.

CANCLINI, Néstor Garcia. As culturas populares no capitalismo. São Paulo: Brasiliense, 1983.

CHAUÍ, Marilena. Cultura e democracia, in: Crítica y Emancipación. Buenos Aires, v.1, no.1, p. 5376, jun. 2008.

DITT, Eduardo et al. Conservação da biodiversidade por meio da atividade extrativista em comunidades quilombolas, in: Revista Brasileira de Ciências Ambientais - Rio de Janeiro, no. 27, p. 1-15, mar. 2013.

ESQUENAZI, S. M. Potencial de uso da fibra da piaçava. Disponível em: http://www.pucrio.br/pibic/relatorio_resumo2015/resumos_pdf/ctch/ARQ/Sofia\%20Moreira\%20Esquenazi.pdf Acesso em: 25 de jun de 2019.

GUIMARÃES, Carlos Alex Lima; SILVA, Luiz Alberto Mattos. Piaçava da Bahia: Do extrativismo à cultura agrícola. Ilhéus (Bahia): Editus, 2012.

KATINSKY, Júlio Roberto. Artesanato moderno, in: Agitprop - Revista Brasileira de Design. São Paulo, ano 1, n. 1, 2008. Disponível em:

http://www.agitprop.com.br/index.cfm?pag=repertorio_det\&id=5\&titulo=repertorio.

Acesso em: 9 ago. 2020.

LIMA, Ricardo. Artesanato: Cinco pontos para discussão. IPHAN, 2002. Disponível em: http://portal.iphan.gov.br/uploads/publicacao/Artesanato_Cinco_Pontos_para_Discussao.pdf. Acesso em: 22de jun de 2019.

MATIAS, Iraldo Alberto Alves. Projeto e Revolução: do fetichismo à gestão, uma crítica à teoria do design. Tese (doutorado). Campinas: Universidade Estadual de Campinas, Instituto de Filosofia e Ciências Humanas, Campinas, 2014.

MATTOS, Luciano Carlos Vital de. Análise econômica e social do plantio da piaçaveira no sudeste da Bahia. Dissertação (Mestrado em Economia) - Faculdade de Ciências Econômicas, Universidade Federal da Bahia, Ilhéus, 2002.

MARX, Karl. O capital: crítica da economia política: livro I. São Paulo: Boitempo, 2017. MARX, Karl. Manuscritos econômico-filosóficos. São Paulo: Boitempo, 2010.

PIMENTEL, N.M. Uso tradicional, manejo e Processamento da piaçava da bahia (attalea funifera mart.). Tese (Doutorado). Universidade de Brasília. Programa de Pós Graduação em Ciências Florestais, Brasília, 2015.

PINTO, Álvaro Vieira. O conceito de tecnologia. Rio de Janeiro: Contraponto, 2005.

RANIERI, Jesus. Trabalho e dialética. São Paulo: Boitempo, 2011.

ROCHA, A. H. S. et al. Desenvolvimento de um eco-compósito usando rejeitos de eva para construção de placas de divisórias, in: Revista Engenharia em Ação UniToledo. Araçatuba (SP), v.1, n.1, p.184-199, out/dez 2016.

SILVA, Marcelo Santana et al. Artesanato de palha de Porto de Sauípe: potencialidade para concessão de Indicação Geográfica, in: INTERNATIONAL SYMPOSIUM ON TECHNOLOGICAL INNOVATION ISTI/SIMTEC , 9, 2018, Aracaju. Proceeding... Aracaju: UFS, 2018, p.885-894. 